\title{
Multimodal Electrophysiological Assessment of Ataxia Telangiectasia
}

\author{
Margot J. Taylor and William J. Logan
}

\begin{abstract}
SUMMARY: We report multimodal evoked response studies in eleven children with ataxia telangiectasia. The ABRs were normal in all but one patient despite the severity of the disorder. The SERs were abnormal in all of the patients, the waveforms being either absent or of delayed latency, the abnormalities were more marked in the older patients. Abnormal motor and sensory nerve conduction studies were also found in all but the younger few patients. Most notably, the VERs were abnormal in all but 2 , the older patients had delayed VERs and most had small amplitude responses. The electrophysiological profile of ataxia telangiectasia patients on the multimodal evoked responses differs from that found in certain other degenerative ataxias studied and may have some diagnostic utility.
\end{abstract}

RÉSUMÉ: Nous rapportons les résultats d'une étude de potentiels évoqués plurimodaux chez 11 enfants atteints d'ataxietélangiectasie. Les potentiels évoqués du tronc cérébral (ABRs) sont normaux chez tous les malades sauf un, malgré la sévérité de l'atteinte clinique. Les potentiels évoqués somesthésiques (SERs) sont tous anormaux; ils le sont davantage chez les enfants plus âgés: les réponses évoquées sont ou absentes, ou retardées. Les études de conduction motrice et sensitive sont elles aussi anormales, sauf chez les plus jeunes enfants. On note plus particulièrement des anomalies du potentiel évoqué visuel (VERs): latences prolongées chez les plus âgés, amplitude réduite chez la plupart. Le profil électrophysiologique de l'ataxie-télangiectasie pour les divers modes de potentiels évoqués diffère de celui qui a été retrouvé dans certaines autres ataxies dégénératives et peut donc être d'un intérêt diagnostique.

Can. J. Neurol. Sci. 1983; 10:261-265

Ataxia telangiectasia is an autosomal recessive neurodegenerative disease characterized by progressive ataxia and other neurologic abnormalities in association with ocular and cutaneous telangiectasia. Patients with this disorder also have an increased frequency of sinopulmonary infection, immunologic deficiency and malignancy. Essentially all cases have increased levels of serum alpha-fetoprotein and an increased percentage of breakage on chromosome analysis (Boder and Sedgwick, 1957; Mason and Gelfand, 1979; Baloh et al., 1978). These findings may serve to confirm the diagnosis in suspected cases.

The ataxia begins in late infancy or early childhood and progresses slowly during the first several years. Progressive sensory disturbance develops later including loss of stretch reflexes and impairment of sensations of proprioception and vibration. Other neurologic abnormalities including choreoathetosis, dysarthria and dysfunction of ocular movements are present in most cases.

The major pathology resides in the cerebellum and consists of atrophy of all cortical layers. Later the dorsal columns of the spinal cord and spinocerebellar tracts show signs of degeneration. These pathologic abnormalities seem sufficient to explain the onset of sensory abnormalities. There is also evidence of axonal degeneration of the peripheral nerves. Martinez et al. (1977) have found a decreased amplitude and conduction velocities of distal motor and sensory evoked nerve potentials similar to those found in patients with Friedreich's ataxia.

Recently a number of investigators have reported abnormalities of central sensory evoked potentials in patients with spinocerebellar and other hereditary degenerations (e.g. Kirkham and Coupland, 1981; Pedersen and Trojaborg, 1981; Bird and Crill, 1981). In many patients the evoked response abnormalities revealed subclinical damage to the sensory systems.

Sensory evoked potentials are a sensitive measure of sensory function and can detect previously unrecognized abnormalities. Since ataxia telangiectasia patients eventually develop clinical abnormalities of certain sensory systems they may well have abnormal sensory evoked responses. The present study evaluates multimodality sensory evoked potentials in 11 ataxia telangiectasia patients and describes specific abnormalities. The pattern of evoked potential disturbance found may be characteristic for this disorder as it is distinctly different from that seen in other degenerative disorders such as Friedreich's ataxia.

\section{METHODS}

\section{Subjects}

Eleven patients ( 6 female) with ataxia telangiectasia were studied. Their ages ranged from 5-26 years (mean 12 years). Twelve neurologically normal children ( 8 female) served as controls. Their ages ranged from $5-16$ years (mean 11 years).

\section{Procedure}

Visual, auditory and somatosensory evoked responses were studied using a Nicolet CA-1000 clinical signal averager. Automatic artefact reject was used throughout to remove unwanted signal due to movement of the patient. The visual evoked responses (VERs) were recorded in response to reversing checkerboard pattern stimulation presented via a television display.

From the Division of Neurology, Departments of Pediatrics and Medicine. University of Toronto, The Hospital for Sick Children, Toronto, Ontario. Received March 1, 1983. Accepted July 18, 1983.

Reprint requests to: Dr. M.J. Taylor, Division of Neurology, The Hospital for Sick Children, 555 University Avenue, Toronto, Ontario M5G IX8. 
The display subtended 12 degrees and the checks $30^{\prime}$ of arc and reversed at a rate of $1.88 / \mathrm{sec}$. The bandpass was $.5-100 \mathrm{~Hz}$, with a gain of $20 \mathrm{k}$ and a sweep of $200 \mathrm{msec}$. VERs were recorded over 01 and 02 referenced to $\mathrm{Fz}$. Sixty-four trials per average were recorded in response to monocular stimulation. Target fixation was monitored in all patients by observing the corneal reflection of the visual display. For all evoked response studies Grass gold cup electrodes were used; electrode impedance was always below 5 Kohms.

Auditory brainstem responses (ABRs) were recorded in response to $100 \mu \mathrm{sec}$ rarefaction monaural click stimuli, presented at 70 or $80 \mathrm{dBHL}$ ( 70 or $80 \mathrm{~dB}$ above average hearing threshold in the lab of 10 adults with normal hearing) and at a rate of $11 / \mathrm{sec}$. Contralateral white noise masking was presented to prevent cross-stimulation. The bandpass was $150-3000 \mathrm{~Hz}$ with a gain of $100 \mathrm{k}$ and a sweep of $10 \mathrm{msec}$. The ABRs were recorded between $\mathrm{Cz}$ and ipsilateral ear. Two averages of 1024 trials were obtained at each intensity level tested for each ear.

Somatosensory evoked responses (SERs) were recorded in response to electrical pulse stimulation to the median nerve at the wrist. Stimulation intensity was gradually increased until a slight thumb movement was observed, and the studies were then run at that level of stimulation. This was determined separately for left and right median nerves. The duration of the pulses was $200 \mu \mathrm{sec}$ and they were presented at $4.1 / \mathrm{sec}$. The bandpass for the SERs was $30-3000 \mathrm{~Hz}$, a gain of $40 \mathrm{k}$ was used and a sweep of 45 or $50 \mathrm{msec}$. The SERs were recorded over the

Table 1: Latency (in msec) of ABR components in ataxia telanglectasla patlents.

\begin{tabular}{ccccccccc}
\hline \hline Patient & I & II & III & IV & V & I-III & III-V & I-V \\
I. R & 1.5 & 2.6 & 3.5 & 4.3 & 5.4 & 2.0 & 1.9 & 3.9 \\
L & 1.9 & 3.1 & 4.0 & 5.1 & 5.9 & 2.1 & 1.9 & 4.0 \\
2. R & 1.6 & 2.6 & 3.7 & - & 5.5 & 2.1 & 1.8 & 3.9 \\
L & 1.6 & 2.6 & 3.7 & 4.4 & 5.5 & 2.1 & 1.8 & 3.9 \\
3. R & 1.8 & 2.9 & 3.9 & 4.9 & 5.7 & 2.1 & 1.8 & 3.9 \\
L & 1.5 & 2.7 & 3.7 & 4.9 & 5.4 & 2.2 & 1.7 & 3.9 \\
4. R & 1.8 & 2.7 & 3.6 & - & 5.5 & 1.8 & 1.9 & 3.7 \\
L & 1.9 & 3.0 & 3.8 & 4.8 & 5.9 & 1.9 & 2.1 & 4.7 \\
5. R & 1.5 & 2.6 & 3.8 & 4.9 & 5.5 & 2.3 & 1.7 & 4.0 \\
L & 1.5 & 2.5 & 3.6 & 4.4 & 5.4 & 2.1 & 1.8 & 3.9 \\
6. R & 1.5 & 2.5 & 3.5 & 4.4 & 5.5 & 2.0 & 2.0 & 4.0 \\
L & 1.5 & 2.5 & 3.6 & 4.4 & 5.4 & 2.1 & 1.8 & 3.9 \\
7. R & 1.8 & 3.0 & 4.0 & - & 5.5 & 2.2 & 1.5 & 3.7 \\
L & 1.9 & 3.0 & 4.0 & - & 5.6 & 2.1 & 1.6 & 3.7 \\
8. R & 1.7 & 2.9 & 3.7 & - & 5.5 & 2.0 & 1.8 & 3.8 \\
L & 1.7 & 2.8 & 3.8 & 4.6 & 5.5 & 2.1 & 1.7 & 3.8 \\
9. R & 1.5 & 2.4 & 3.5 & 4.5 & 5.4 & 2.0 & 1.9 & 3.9 \\
L & 1.4 & 2.3 & 3.4 & 4.2 & 5.2 & 2.0 & 1.8 & 3.8 \\
10. R & 1.4 & 2.9 & 3.8 & 5.1 & 5.7 & $2.4 *$ & 1.9 & 4.3 \\
L & 1.3 & 2.7 & 3.7 & 4.8 & 5.5 & $2.4 *$ & 1.8 & 4.2 \\
11. R & 1.7 & 2.6 & 3.6 & 4.8 & 5.6 & 1.9 & 2.0 & 3.9 \\
L & 1.7 & 2.7 & 3.8 & 4.6 & 5.7 & 2.1 & 1.9 & 4.0 \\
Norms & & & & & & & & \\
means: & 1.7 & 2.7 & 3.7 & 4.9 & 5.6 & 2.0 & 1.9 & 3.9 \\
s.d.: & .20 & .17 & .20 & .25 & .20 & .12 & .15 & .17 \\
upper limits: & 2.2 & 3.1 & 4.2 & 5.5 & 6.1 & 2.3 & 2.2 & 4.3 \\
\hline *ing & & & & & & & & \\
\hline
\end{tabular}

*increased latency postcentral contralateral hemisphere $\left(\mathrm{C}^{\prime}\right.$ and $\mathrm{C}^{\prime}, 2 \mathrm{~cm}$ posterior to $\mathrm{C} 3$ and $\mathrm{C} 4$ ) referenced to $\mathrm{Fpz}$.

Sensory and motor nerve conduction studies were also completed on nine of the patients. Motor conduction velocities were determined by supramaximal surface stimulation to the nerve trunks at two sites along their course - wrist and elbow or ankle and knee. The muscle action potential was recorded with surface electrodes over the appropriate muscle belly and the latency was taken at the onset of take-off of the potential from the baseline. Sensory nerve action potentials were recorded with surface electrodes over the median nerve at the wrist. The stimulus was presented with ring electrodes applied to the index finger. The sensory action potential in the sural nerve was produced by stimulating the nerve antidromically with surface electrodes in the posterior aspect of the calf and recording with surface electrodes behind the lateral malleolus at the ankle.

\section{RESUlTS}

The data are summarized in Tables 1-4. All of the children had normal ABRs (Table 1), with the exception of patient \#10 who had unexplained increased I-III interpeak latencies. None of the children had the ABR abnormalities characteristic of Friedreich's ataxia, progressive loss of the later waves. Five patients had one or more abnormally prolonged VERs, with latencies more than 2.5 standard deviations $(p<.01)$ beyond the normal limits (Table 2). The mean amplitude of the VERs was

Table 2: Latency and amplitude of VERs in ataxia telanglectasia patients.

\begin{tabular}{|c|c|c|c|c|}
\hline Patient & $\begin{array}{l}\text { Latency } \\
\text { (msec) }^{02}\end{array}$ & $\begin{array}{l}\text { Amplitude } \\
(\mu \mathrm{V})\end{array}$ & $\begin{array}{l}\text { Latency } \\
\text { (msec) }^{01}\end{array}$ & $\begin{array}{c}\text { Amplitude } \\
(\mu V)\end{array}$ \\
\hline I. L & 104 & 10.0 & 108 & 7.5 \\
\hline $\mathbf{R}$ & 100 & 8.2 & 108 & $2.7^{*}$ \\
\hline 2. $\mathrm{L}$ & 105 & 10.2 & 104 & 13.5 \\
\hline $\mathbf{R}$ & $114+$ & 7.8 & 106 & 10.8 \\
\hline 3. L & 98 & 14.2 & 100 & 12.5 \\
\hline $\mathbf{R}$ & 101 & 12.0 & 110 & 8.5 \\
\hline 4. L & 104 & 8.6 & 104 & 6.0 \\
\hline $\mathbf{R}$ & $115+$ & 9.3 & 107 & 7.0 \\
\hline 5. L & 106 & $1.6^{*}$ & 106 & $2.3^{*}$ \\
\hline $\mathbf{R}$ & $111+$ & $2.6^{*}$ & $111+$ & $3.6^{*}$ \\
\hline 6. L & 107 & $4.7^{*}$ & 108 & $2.1^{*}$ \\
\hline $\mathbf{R}$ & 108 & 5.5 & 106 & $3.5^{*}$ \\
\hline 7. L & 99 & 7.4 & 102 & 6.7 \\
\hline $\mathbf{R}$ & 96 & 7.5 & 100 & 8.5 \\
\hline 8. L & 104 & $2.2^{*}$ & 97 & 4.8 \\
\hline $\mathbf{R}$ & 97 & $4.2^{*}$ & 98 & 4.9 \\
\hline 9. L & $112+$ & $2.0^{*}$ & 108 & $2.9^{*}$ \\
\hline $\mathbf{R}$ & - & - & - & - \\
\hline 10. L & $118+$ & 5.1 & $130+$ & $1.8^{*}$ \\
\hline $\mathbf{R}$ & $145+$ & 7.9 & $146+$ & $4.5^{*}$ \\
\hline \multicolumn{5}{|c|}{ 11. Not Tested } \\
\hline \multicolumn{5}{|l|}{ Norms: } \\
\hline Means: & 97 & 15.5 & & \\
\hline s.d.: & 5.1 & 4.3 & & \\
\hline
\end{tabular}


Table 3: Latencies (in msec) of SER components in ataxia telangiectasia - standardized by arm length to age-matched controls.

\begin{tabular}{|c|c|c|c|c|c|c|c|c|c|}
\hline Patient & Age & N13 & P15 & N18 & P22 & $\begin{array}{l}\text { N13- } \\
\text { N18 }\end{array}$ & $\begin{array}{l}\text { P15- } \\
\text { N18 }\end{array}$ & $\begin{array}{l}\text { N18- } \\
\text { P22 }\end{array}$ & $\begin{array}{l}\text { P15- } \\
\text { P22 }\end{array}$ \\
\hline \multirow[t]{2}{*}{1.} & $5 \mathrm{R}$ & - & $15.1^{*}$ & $19.6^{*}$ & $23.5^{*}$ & - & 4.5 & 3.9 & $8.4^{*}$ \\
\hline & L & - & 14.5 & $18.4^{*}$ & $23.7^{*}$ & - & 3.9 & 5.3 & $9.2^{*}$ \\
\hline \multirow[t]{2}{*}{2.} & $7 \mathrm{R}$ & 9.7 & $13.5^{*}$ & $16.9^{*}$ & $22.1^{*}$ & $7.0^{*}$ & 3.4 & 5.2 & $8.6^{*}$ \\
\hline & $\mathbf{L}$ & $11.9^{*}$ & $13.5^{*}$ & $17.3^{*}$ & $21.0^{*}$ & 5.4 & 3.8 & 3.7 & 7.5 \\
\hline \multirow[t]{2}{*}{3.} & $8 \mathrm{R}$ & $11.1^{*}$ & $13.4^{*}$ & $17.2^{*}$ & $20.4^{*}$ & 5.9 & 3.8 & 3.2 & 7.0 \\
\hline & L & 10.3 & $12.7^{*}$ & 15.9 & $20.1^{*}$ & 5.6 & 3.2 & 4.2 & 7.4 \\
\hline \multirow[t]{2}{*}{4.} & $9 \mathrm{R}$ & - & $13.5^{*}$ & $17.2^{*}$ & $20.2^{*}$ & - & 3.7 & 3.0 & 6.7 \\
\hline & $\mathbf{L}$ & - & $14.7^{*}$ & $18.0^{*}$ & $20.7^{*}$ & - & 3.3 & 2.7 & 6.0 \\
\hline 5. & $10 \mathrm{~L}$ & - & $15.2^{*}$ & $17.7^{*}$ & $20.5^{*}$ & - & 2.5 & 2.8 & 5.3 \\
\hline \multirow[t]{2}{*}{6.} & $11 \mathrm{R}$ & - & $14.3^{*}$ & $16.9^{*}$ & 19.7 & - & 2.5 & 2.8 & 5.3 \\
\hline & $\mathbf{L}$ & - & $13.2^{*}$ & $17.5^{*}$ & $21.1^{*}$ & - & 4.3 & 3.6 & 7.9 \\
\hline \multirow[t]{2}{*}{7.} & $11 \mathrm{R}$ & 10.4 & 12.4 & 16.2 & 18.8 & $8.4^{*}$ & 3.8 & 2.6 & 6.4 \\
\hline & L & $10.9^{*}$ & $12.9^{*}$ & 15.7 & 19.0 & $8.1^{*}$ & 2.8 & 3.3 & 6.1 \\
\hline \multirow[t]{2}{*}{8.} & $13 R$ & - & 14.0 & 17.2 & 21.2 & - & 3.2 & 4.0 & 7.2 \\
\hline & L & - & $17.3^{*}$ & $21.6^{*}$ & $24.5^{*}$ & - & 4.3 & 3.9 & $8.2^{*}$ \\
\hline \multirow[t]{2}{*}{9.} & $17 R$ & - & $a b$ & $a b$ & $a b$ & - & $a b$ & $a b$ & $a b$ \\
\hline & L & - & $17.3^{*}$ & $19.9^{*}$ & $26.7^{*}$ & - & 2.6 & $6.8^{*}$ & $9.4^{*}$ \\
\hline 10. & $16 \mathrm{~L}$ & - & $\mathrm{ab}$ & $a b$ & $a b$ & - & $a b$ & $a b$ & $a b$ \\
\hline
\end{tabular}

- not tested

* significantly delayed compared to age-matched controls ab no response recorded

Table 4: Motor and sensory nerve conductlon studies In ataxia telanglectasia.

\begin{tabular}{|c|c|c|c|c|}
\hline \multirow[b]{2}{*}{ Patient } & \multicolumn{2}{|c|}{ motor velocities $(\mathrm{m} / \mathrm{s})$} & \multicolumn{2}{|c|}{ sensory velocities $(\mathrm{m} / \mathrm{s})$} \\
\hline & ulnar & peroneal & median & sural \\
\hline 1. & 53.5 & 48.2 & 一 & 51.4 \\
\hline 2. & 58.6 & 50.5 & 46.8 & 38.0 \\
\hline 3. & 62.0 & 56.3 & 48.0 & 38.0 \\
\hline 4. & 53.5 & 44.0 & $32.1^{*}$ & 一 \\
\hline 5. & $32.9^{*}$ & 54.1 & $44.9^{*}$ & abs \\
\hline 6. & 51.2 & 46.6 & $34.3^{*}$ & - \\
\hline 7. & - & - & - & 一 \\
\hline 8. & - & - & 一 & 一 \\
\hline 9. & $48.9^{*}$ & 42.8 & abs & abs \\
\hline 10. & $48.1^{*}$ & $39.8^{*}$ & abs & abs \\
\hline 11. & $46.8^{*}$ & $27.2^{*}$ & abs & abs \\
\hline \multicolumn{5}{|l|}{ normals: } \\
\hline means: & 65.4 & 57.5 & 56.9 & 40.0 \\
\hline s.d.: & 5.8 & 6.9 & 4.0 & 2.7 \\
\hline lower limits & 51.0 & 40.3 & 46.9 & 33.3 \\
\hline
\end{tabular}

* decreased velocities

- not tested

significantly smaller in ataxia telangiectasia $(F(1,54)=31.93$, $\mathrm{p}<.001$ ); all the patients' VER amplitudes fell below the normal mean, six had a response from at least one eye significantly smaller than the normal range (figure 1). Of the 10 children who had SER studies done all had SER abnormalities; the latencies were increased beyond the normal range of age-matched controls $(p<.01)$ or the waves were completely absent (Table 3 ). Absent SERs were found only in the oldest patients.

Motor nerve conduction studies were normal in five of the younger children, the remainder had decreased conduction velocity. The sensory nerve conduction studies were normal in the three youngest patients and of decreased velocity or absent in the others tested (Table. 4).
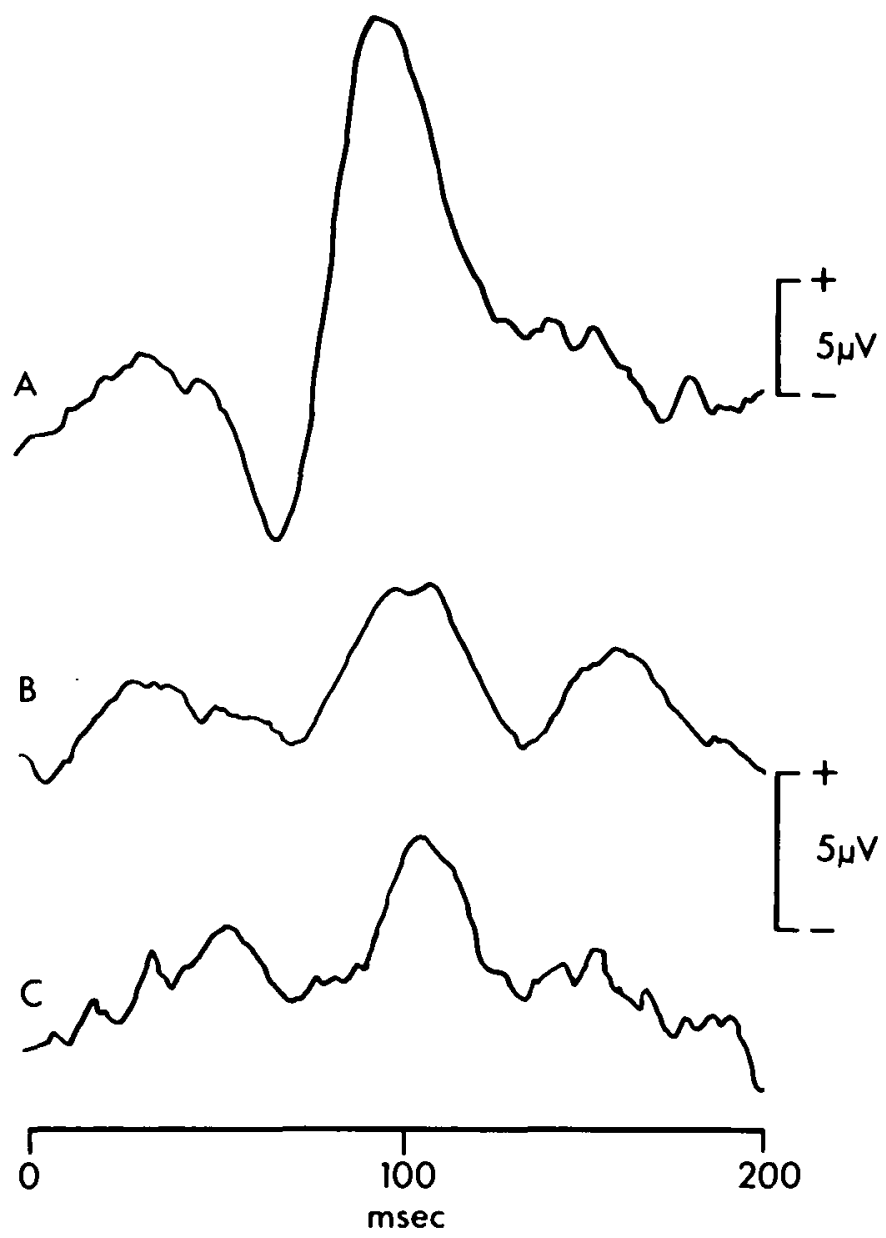

Figure I - VERsfrom a normal child (A) and 2 patients with ataxia telangiectasia $(B$ and $C)$ showing the greatly reduced amplitude which was found in 6 of our cases.

\section{Discussion}

The present study has demonstrated a high incidence of sensory system dysfunction in these patients with ataxia telangiectasia. We believe this is the first report of VER and SER abnormalities in this disorder. Although Nuwer et al. (1983) included three ataxia telangiectasia patients in a large group of various inherited ataxias, he failed to report the specific abnormalities in these three patients. Eighty percent of the patients we tested had VER abnormalities and all had SER abnormalities. As is often found with evoked potential abnormalities in hereditary degenerative ataxias (e.g., Kirkham and Coupland, 1981; Pedersen and Trojaborg, 1981), this methodology appears to detect subclinical manifestations of the disease. 
Oculomotor abnormalities are frequently seen in ataxia telangiectasia patients but these alterations should not produce delayed VERs found in 5 of the 11 cases studied here. A decreased amplitude of VERs appeared to be typical for this group of patients but was profound in 6 of the cases. This could be attributable to the worsening oculomotor disorders in the older patients, however as they were able to maintain fixation, this is unlikely. A decreased amplitude of responses is more likely associated with either a decrease in the number of conducting fibres in the sensory pathway, or a greater dispersion of the afferent volley in the transmission through the sensory system. The latter, however, produces flattened responses and increased interpeak latencies, neither of which was a feature of our data. Jones et al. (1980), Carroll et al. (1980) and Kirkham and Coupland (1981) have all argued that increased VER latencies with decreased amplitudes, as found in Friedreich's ataxia patients, are best explained by progressive loss of nerve fibres in the visual pathway; this has been supported by some neuropathological studies (e.g., Oppenheimer, 1979). The lack of significant interocular differences in our patients suggests a generalized defect involving both visual pathways; this again is similar to that found in other degenerative ataxias (Bird and Crill, 1981). A recent study has reported retinal involvement in Friedreich's ataxia which could also influence the VER's (Kirkham and Coupland, 1981); it would be of interest to determine if ataxia telangiectasia patients also have electroretinal as well as VER abnormalities.

The SER abnormalities were found in all the patients, reflecting some dysfunction of the posterior column thalamocortical pathways. Since several of these patients did not report decreased pressure/touch sensitivity or proprioception, the modalities largely utilizing these pathways, the evoked potential evaluation detected asymptomatic damage. Abnormal SERs have been reported in other degenerative ataxia patients, particularly in Friedreich's ataxia (Noel and Desmedt, 1980). The loss or radical slowing of the cortical responses is the most commonly reported finding in Friedreich's ataxia. Peripheral conduction time, when it can be measured, is usually normal although the response is of very small amplitude (Sauer and Schenck, 1977; Jones et al., 1980; Pedersen and Trojaborg, 1981). We did not measure peripheral SERs in most of our patients, but the nerve conduction studies indicated increasing peripheral nerve abnormalities with age. Also, the absolute wave latencies were more often increased than were the interpeak latencies, which reflect central conduction. This suggests that both peripheral and central sensory neuronal degeneration could be occurring in these patients and is consistent with the observation of Martinez et al. (1977) of peripheral conduction abnormalities in ataxia telangiectasia patients.

While most reported electrophysiological abnormalities in the ataxias are largely descriptive, defining further the extent of neurologic involvement, they have had little diagnostic utility. Recently Nuwer et al. (1983) contrasted a group of Friedreich's ataxia and a group of various inherited ataxia patients and concluded that evoked potentials were not remarkable at distinguishing between the two. We suggest that this is due to their combining small numbers of dissimilar ataxia patients into a single group. We find evoked potentials to be quite useful in discriminating among ataxia patients, particularly using ABR abnormalities to facilitate diagnosis of Friedreich's ataxia (Taylor et al., 1982; Taylor, 1983). The electrophysiological profiles of the ataxia telangiectasia patients reported here are also distinct from those found in other degenerative ataxias that we have studied. Both the VERs and the SERs appeared to worsen with age and the severity of the disease, whereas the ABRs remained normal throughout. VERs have not been found to be correlated with the stage of disease in other ataxias, nor have consistent amplitude abnormalities been reported. SERs are usually abnormal in patients with degenerative ataxias and the present results demonstrate that this is also true in patients with ataxia telangiectasia. The combination of electrophysiological data from all three sensory modalities appears to be distinctive in the children with ataxia telangiectasia and may have significant diagnostic utility in the differentiation of these patients from those with other progressive hereditary ataxias. There is need, however, for systematic multimodality electrophysiological assessment of typical and atypical degenerative ataxias to confirm this possibility.

\section{ACKNOWLEDGEMENTS}

This research was supported in part by the Grotto Cerebral Palsy Foundation.

\section{REFERENCES}

Baloh, R.W., Yee, R.D., Boder, E. (1978). Eye Movements in Ataxia Telangiectasia. Neurology 28: 1099-1104.

Bird, T.D., Crill, W.E. (1981). Pattern-Reversal Visual Evoked Potentials in the Hereditary Ataxias and Spinal Degenerations. Ann. Neurol. 9:243-250.

Boder, E., Sedgwich, R.P. (1957). A Familial Syndrome of Progressive Cerebellar Ataxia Oculocutaneous Telangiectasia, and Frequent Pulmonary Infection. A Preliminary Report on 7 Children, and Autopsy, and a Case History. University of Southern California Medical Bulletin 9:15-22.

Bouchard, J.P, Barbeau, A., Bouchard, R., Bouchard, R.W. (1979). Electromyography and Nerve Conduction Studies in Friedreich's Ataxia and Autosomal Recessive Spastic Ataxia of CharlevoixSaguenay (ARSACS). Can. J. Neurol. Sci. 6:185-189.

Carroll, W.M., Kriss, A., Baraitser, M., Barrett, G., Halliday, A.M. (1980). The Incidence and Nature of Visual Pathway Involvement in Friedreich's Ataxia. A Clinical and Visual Evoked Potential Study of 22 Patients. Brain 103:413-434.

Jones, S.J., Baraitser, M., Halliday, A.M. (1980). Peripheral and Central Somatosensory Nerve Conduction Defects in Friedreich's Ataxia. J. Neurol., Neurosur., and Psychiatry 43:495-503.

Kirkham, T.H., Coupland, S.G. (1981). An Electroretinal and Visual Evoked Potential Study in Friedreich's Ataxia. Can. J. Neurol. Sci. 8:289-294.

Livingstone, I.R., Mastaglia, F.L., Edis, R., Howe, J.W. (1981). Visual Involvement in Friedreich's Ataxia and Hereditary Spastic Ataxia. Arch. Neurol. 38:75-79.

Martinez, A-Cruz, Bariro, M., Gutierrez, A.M., Lopez, E. (1976). Abnormalities in Sensory and Mixed Evoked Potentials in Ataxia Telangiectasia. J. Neur., Neurosur., and Psychiatry 40:44-49.

Noel, P., Desmedt, J.E. (1980). Cerebral and Far-Field Somatosensory Evoked Potentials in Neurological Disorders Involving the Cervical Spinal Cord, Brainstem, Thalamus and Cortex. Prog. Clin. Neurophysiol. 7:205-230.

Nuwer, M.R., Perlman, S.L., Packwood, J.W., Kark, R.A.P. (1983). Evoked Potential Abnormalities in the Various Inherited Ataxias. Ann. Neurol., 13:20-27.

Oh, S.J., Halsey, J.H. (Jr.) (1973). Abnormality in Nerve Potentials in Friedreich's Ataxia. Neurology 23:52-54.

Oppenheimer, D.R. (1979). Brain Lesions in Friedreich's Ataxia. Can. J. Neurol. Sci. 6:173-176.

Pedersen, L., Trojaborg, W. (1981). Visual, Auditory and Sornatosensory Pathway Involvement in Hereditary Cerebellar Ataxia, Friedreich's Ataxia and Familial Spastic Paraplegia. Electroenceph. and Clinical Neurophys. 52:283-297. 
Sauer, M., Schenck, E. (1977). Electrophysiologic Investigations in Freidreich's Heredoataxia and in Hereditary Motor and Sensory Neuropathy. Electrograph. and Clinical Neurophys. 43:623.

Satya-Murti, S., Cacace, A., Hanson, P. (1980). Auditory Dysfunction in Friedreich Ataxia: Result of Spiral Ganglion Degeneration. Neurology 30: 1047-1053.

Shanon, E., Himelfarb, M.Z., Gold, S. (1981). Auditory Function in Friedreich's Ataxia. Electrophysiologic Study of a Family. Arch Otolaryngol 107: 254-256.
Taylor, M.J. (1983). Auditory Brainstem Responses in Friedreich's Ataxia. Letter to the Editor. Ann. Neurol,, in press.

Taylor, M.J., McMenamin, J. B., Andermann, E., Watters G.V. (1982). Electrophysiological Investigation of the Auditory System in Friedreich's Ataxia. Can. J. Neurol. Sci. 9:131-135. 